\title{
Multidisciplinary teams as standard of care in inflammatory bowel disease
}

\author{
Subrata Ghosh FRCPC FRCP FRCPE FCAHS, Editor-in-Chief
}

\begin{abstract}
Inflammatory bowel diseases (IBD), ulcerative colitis and Crohn disease have been associated with extraintestinal manifestations. These include arthralgia and arthritis, erythema nodosum, pyoderma gangrenosum, primary sclerosing cholangitis and autoimmune hepatitis, episcleritis and uveitis. Increasingly, other conditions, such as psoriasis and multiple sclerosis, have been described to be associated with IBD. It may be proper to consider IBD to be one of a spectrum of immune-mediated inflammatory diseases (IMIDs) clustered according to genetic predisposition and immunological imbalance. In general, IMIDs affect young people at the peak of their working life and, therefore, are associated with a high societal cost (1). Extraintestinal manifestations are important predictors of morbidity and temporary work disability (1).
\end{abstract}

IBD is managed by gastroenterologists and, when required, by colorectal surgeons, but ideally should be managed in the setting of a multidisciplinary team. In the current issue of the Canadian Journal of Gastroenterology, this is illustrated by the report from Maastricht (The Netherlands) by Stolwijk et al (2) (pages 199-205) demonstrating the high prevalence of self-reported musculoskeletal spondyloarthropathy $(\mathrm{SpA})$ in patients with IBD. However, one-half of these patients never consulted a rheumatologist. The population-based cumulative incidence of $\mathrm{SpA}$ in Crohn disease is reported to be $6.7 \%$ at 10 years, $13.9 \%$ at 20 years and $18.6 \%$ at 30 years. However, this may have missed patient-reported musculoskeletal symptoms. Lack of rheumatology referral misses an opportunity for accurate diagnosis, appropriate imaging and management strategies. SpA may follow a disease course separate from the activity of IBD and, therefore, may warrant therapeutic strategies dictated by musculoskeletal disease burden and morbidity. These include consideration of nonsteroidal anti-inflammatory drugs (NSAIDs) in the context of IBD, immunosuppressive drugs and antitumour necrosis factor (anti-TNF) agents. SpAs are also a group of overlapping, chronic inflammatory rheumatic diseases; therefore, accurate phenotyping is important for management. Musculoskeletal symptoms may also be a side effect of drug therapy in IBD such as delayed hypersensitivity reactions to anti-TNF agents, thiopurines, nutritional deficiencies and corticosteroid withdrawal. Equally important is to recognize that gastrointestinal symptoms in patients with SpA may be a manifestation of IBD and require investigation by a gastroenterologist.

In general, the extraintestinal manifestations of IBD and the associated IMIDs respond to anti-TNF therapy, except primary sclerosing cholangitis. However, the use of etanercept may rarely be associated with development of IBD. Etanercept is ineffective in IBD and, therefore, $\mathrm{SpA}$ in the presence of IBD should be treated with the anti-TNF monoclonal antibodies. Other IMIDs, such as psoriasis and druginduced lupus, may manifest while under treatment with anti-TNF agents. While some of these manifestations may require discontinuation of anti-TNF therapy, others may be managed while continuing anti-TNF therapy (such as methotrexate for psoriasis).

Multidisciplinary IMID clinics are, therefore, a very effective organizational structure that can assess the entire disease spectrum in patients with IBD to determine the full burden of disease. Although rheumatologists, dermatologists and gastroenterologists represent key members of such multidisciplinary IMID teams, ophthalmologists and hepatologists also participate (Box 1). Such teams are effective in coordinating trials, learning from one anothers' management algorithms and ensuring effective management of the entire disease burden (Box 2). In academic centres, this should become the standard of care. Such collaborative teams enhance quality of care and may reduce disease burden and morbidity.

\begin{tabular}{|c|c|}
\hline \multicolumn{2}{|c|}{$\begin{array}{c}\text { BOX } 1 \\
\text { Collaborative clinical care teams in } \\
\text { inflammatory bowel disease }\end{array}$} \\
\hline $\begin{array}{l}\text { Multiple specialties } \\
\text { Surgeons: colorectal, general } \\
\text { Rheumatologists } \\
\text { Dermatologists } \\
\text { Hepatologists } \\
\text { Opthalmologists }\end{array}$ & $\begin{array}{l}\text { Mutiple support services } \\
\text { Radiologists } \\
\text { Nutritioinsts } \\
\text { Nurse practitioners } \\
\text { Clinical psychologists } \\
\text { Social workers } \\
\text { Primary care }\end{array}$ \\
\hline \multicolumn{2}{|c|}{$\begin{array}{l}\text { BOX } 2 \\
\text { Collaborative models in inflammatory bowel disease (IBD) }\end{array}$} \\
\hline $\begin{array}{cc}\text { Research } & \text { Clincal } \\
\text { Clinical trials } & \text { IBD care teams } \\
\text { Traditrional studies } & \\
\text { Genetic studies } & \\
\text { Biomarker studies } & \end{array}$ & $\begin{array}{c}\text { Educational } \\
\text { Patients } \\
\text { Physicians } \\
\text { Health care providers }\end{array}$ \\
\hline
\end{tabular}

\section{REFERENCES}

1. Siebert U, Wurm J, Gothe RM, et al; the Swiss IBD Cohort Study Group. Predictors of Temporary and Permanent Work Disability in Patients With Inflammatory Bowel Disease: Results of the Swiss Inflammatory Bowel Disease Cohort Study. Inflamm Bowel Dis 2013, February 26. [Epub ahead of print]

2. Stolwijk C, Pierik M, Landewé, Masclee A, van Tubergen A. Prevalence of self-reported spondyloarthritis features in a cohort of patients with inflammatory bowel disease. Can J Gastroenterol 2013;27:199-205.

3. Shivashankar R, Loftus EV Jr, Tremaine WJ, et al. Incidence of spondyloarthropathy in patients with Crohn's disease: A population-based study. J Rheumatol 2012;39:2148-52.

\section{Department of Medicine, University of Calgary, Calgary, Alberta}

Correspondence: Dr Subrata Ghosh, Department of Medicine, Division of Gastroenterology, University of Calgary, 3280 Hospital Drive

Northwest, Calgary, Alberta T2N 4N1. Telephone 403-944-8222, fax 403-944-1095, e-mail subrata.ghosh@albertahealthservices.ca Received and accepted for publication March 8, 2013 


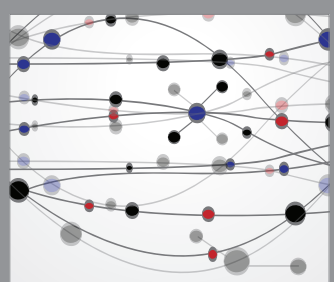

The Scientific World Journal
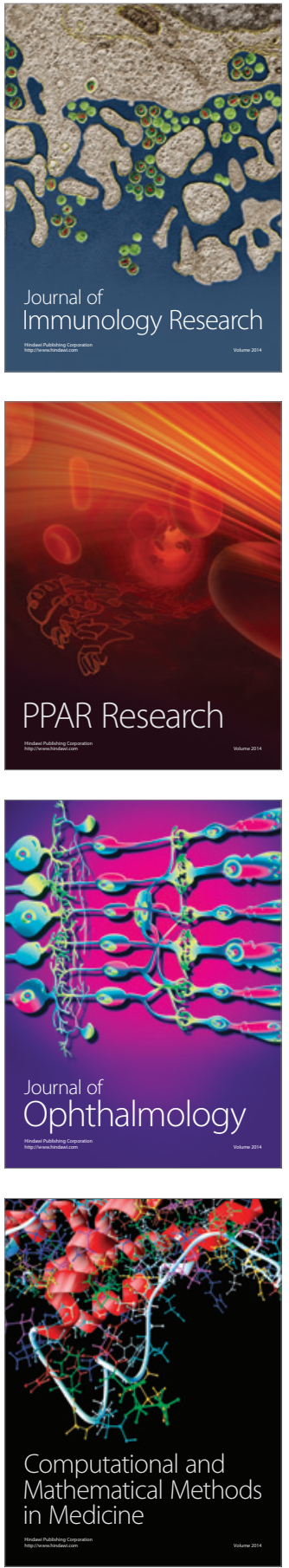

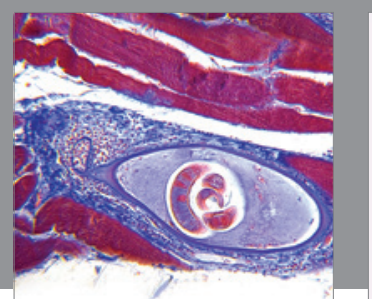

Gastroenterology Research and Practice

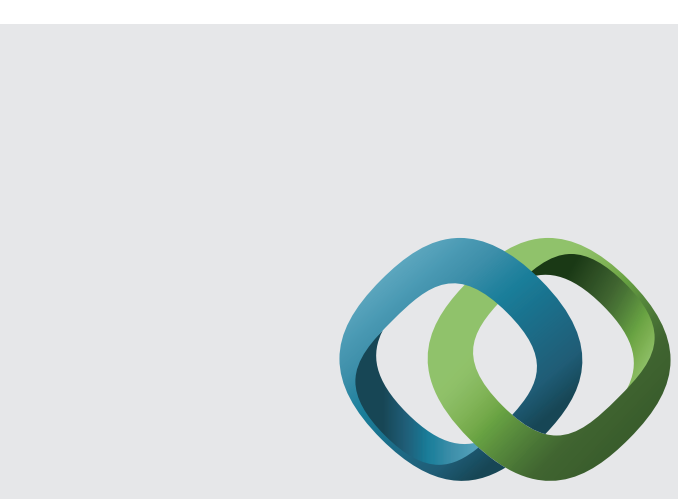

\section{Hindawi}

Submit your manuscripts at

http://www.hindawi.com
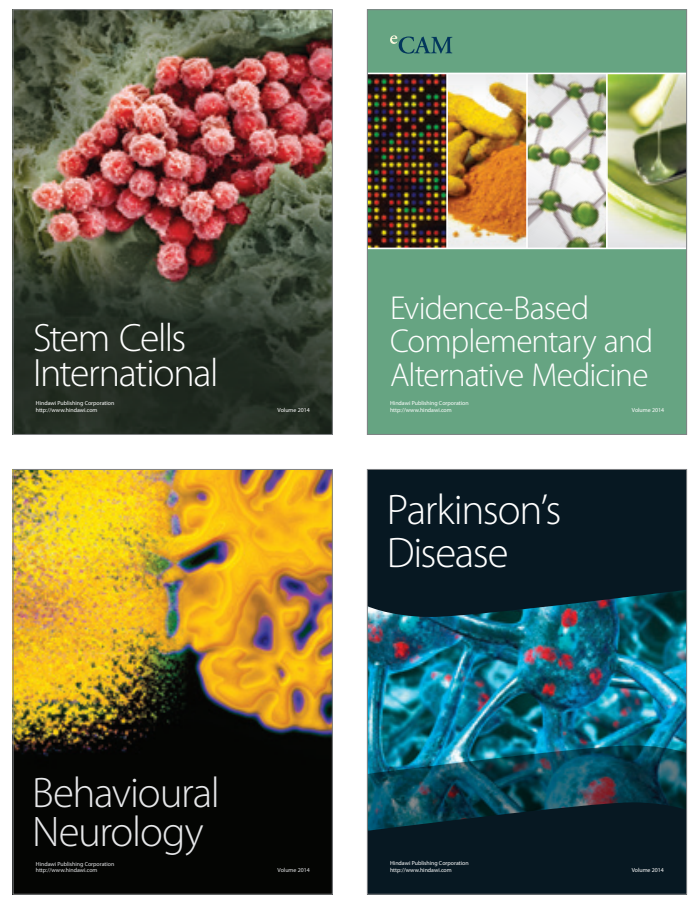
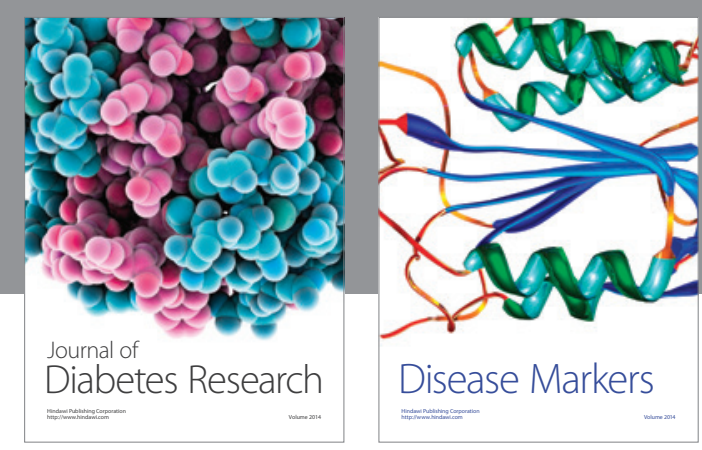

Disease Markers
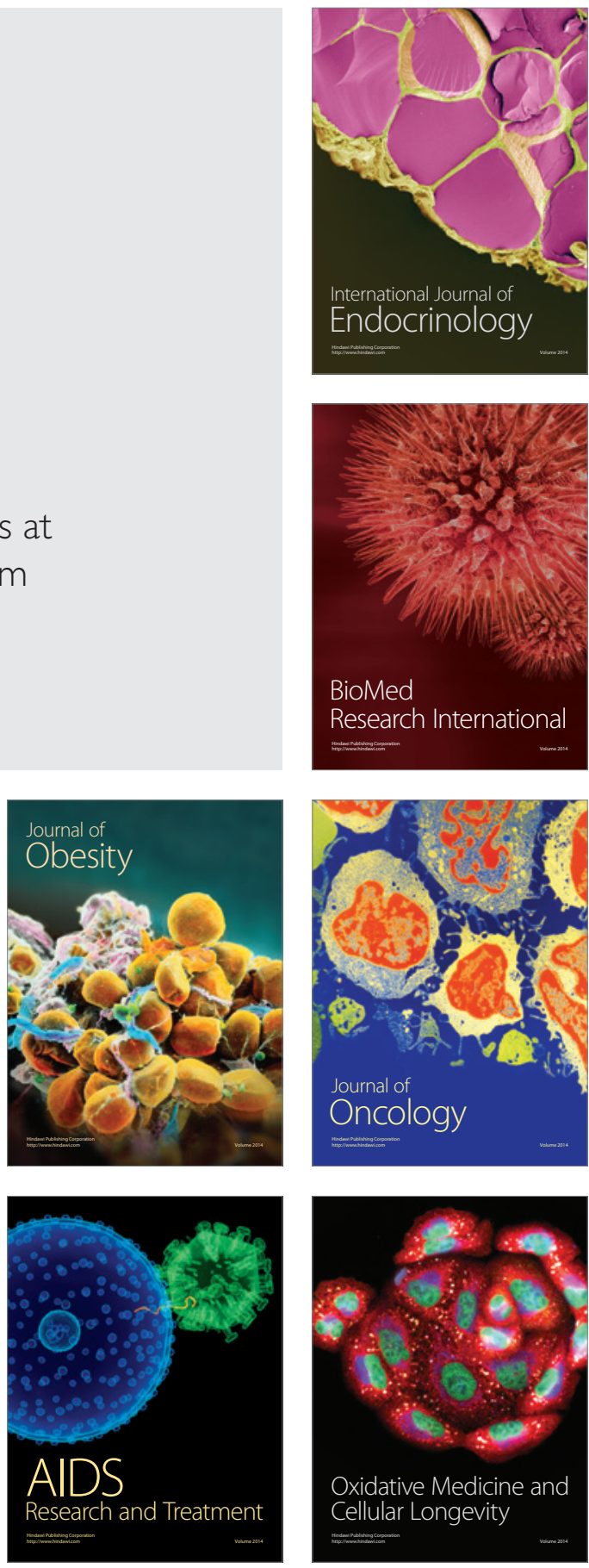